\title{
Performance polínica em cacaueiros (Theobroma cacao L.) autocompatíveis e autoincompatíveis
}

\author{
PAULA ROBERTA ESTEVES DE GODOY ${ }^{1}$, MARGARETE MAGALHÃES SOUZA ${ }^{1,2}$, \\ FRANCISVALDO AMARAL ROZA ${ }^{1}$, PABLIANE RAMOS LAWINSCKY', \\ IONÁ SANTOS ARAÚJO' ${ }^{1}$ e DÁRIO AHNERT ${ }^{1}$
}

(recebido: 07 de agosto de 2008; aceito: 22 de abril de 2009)

\begin{abstract}
Pollen performance in self-compatible and self-incompatible cacao trees (Theobroma cacao L.)). An adequate level of pollinization is necessary for abundance in fruit production. The economic importance of the cacao trees is mainly found in its fruit production from which the seeds are extracted and used as raw material in chocolate manufacturing. Several factors can interfere with the production, but the reproductive characteristics of the cacao tree and their influence on the fructification have not been extensively studied. Moreover, some genotypes are self-incompatible, but self-compatible clones are also found in the commercial populations. In order to compare the pollen performance and the reproduction process between the selfcompatible clones CCN51, and the self-incompatible clones TSH1188 clones, were made studies of germination in vitro (using two tests) and the pollen grain-ovule ratio (P:O). Test 1 (media without some essential elements but with a higher concentration of sacarose) gave better results for pollen germination, with averages higher than $77 \%$, while in test 2 the highest was $39.95 \%$. The percentage of pollen germinated in vitro was higher in self-incompatible plants. Based on the P:O ratio, both clones were classified as obligate autogamous, which was considered a deviation from Cruden classification.
\end{abstract}

Key words - cacao, in vitro germination, ovule, pollen

RESUMO - (Performance polínica em cacaueiros (Theobroma cacao L.) autocompatíveis e autoincompatíveis). A importância econômica do cacaueiro se deve, principalmente, à produção de frutos, dos quais se extraem sementes que servem como matéria prima para a fabricação do chocolate. Vários fatores podem interferir na produção, porém as características reprodutivas do cacaueiro e sua influência na frutificação não têm sido intensamente estudadas. Além disso, alguns genótipos são autoincompatíveis, mas clones autocompatíveis são encontrados em populações comerciais. Com o objetivo de comparar a performance do pólen e o modo de reprodução entre clones autocompatíveis CCN51 e autoincompatíveis TSH1188, foram realizadas estudos de germinação in vitro (utilizando-se dois testes) e da razão pólen-óvulo (P:O). O Teste 1 (meio de cultura sem alguns elementos essenciais e com maior concentração de sacarose) proporcionou melhores resultados de germinação do pólen, com médias acima de 77\%, enquanto que com o Teste 2 o máximo de pólen germinado foi, em média, de 39,95\%. O percentual de pólen germinado in vitro foi maior em plantas autoincompatíveis. Com base na razão P:O, ambos os clones foram classificados como autógamos obrigatórios, o que foi considerado um desvio da classificação de Cruden.

Palavras-chave - cacau, germinação in vitro, óvulo, pólen

\section{Introdução}

Entre os fatores que determinam a produção do cacaueiro, Theobroma cacao L., estão os de natureza ecológica (clima e solo), genética (precocidade, produtividade e qualidade), agronômica e de manejo (Pinto et al. 1998). A produtividade nas plantas de valor comercial está associada não só a fatores endógenos, que podem interferir no processo da floração (Müller \& Valle

1. Universidade Estadual de Santa Cruz (UESC), Depto. de Ciências Biológicas, Pavilhão Jorge Amado, Rod. Ilhéus-Itabuna, km 16, 45662-000 Ilhéus, BA, Brasil.

2. Autora para correspondência: souzamagg@yahoo.com.br.
2007), mas também ao potencial genético e ao caráter de compatibilidade do material (Pinto et al. 1998). O cacaueiro apresenta o fenômeno da incompatibilidade sexuada, que se manifesta quando o pólen de uma flor em uma planta não consegue fecundar os óvulos das flores da mesma planta (autoincompatibilidade) ou de outras plantas (interincompatibilidade) (Enriquez 1985). Assim, o cacaueiro necessita de autopolinização ou de polinização cruzada, que é realizada por micromoscas Forcipomya (Young 1982), e não havendo polinização adequada, a lavoura não produz satisfatoriamente.

Segundo Carletto \& Soria (1973), as primeiras observações sobre a incompatibilidade em cacaueiro datam de 1925. A autoincompatibilidade no cacaueiro 
é complexa, única entre plantas superiores e ainda pouco compreendida, por ocorrer no saco embrionário (Castro \& Bartley 1983), sob ambos os controles genéticos, tanto esporofítico quanto gametofítico (Nettancourt 1977), levando a planta à alogamia. Em plantas alógamas, é desejável que um grande número de grãos de pólen (GP) sejam hábeis à fertilização, pois cada um leva consigo a informação genética conseqüente da heterozigose (Souza et al. 2002). Assim, este trabalho teve como objetivos comparar plantas autocompatíveis e autoincompatíveis em relação à performance do pólen, e também inferir sobre seu modo de reprodução.

\section{Material e métodos}

Germoplasma, delineamento experimental e análise estatística - Foram utilizados clones de cacaueiros autocompatíveis CCN51 e autoincompatíveis TSH1188, mantidos na coleção da Ceplac. Utilizou-se o delineamento inteiramente ao acaso, constando de cinco plantas (repetições) de cada clone. Botões florais foram protegidos um dia antes da abertura da flor, e as flores foram coletadas durante a manhã e transportadas do campo ao laboratório em placas de petri. Os valores de cada repetição correspondem à média de cinco flores analisadas. A análise de variância (ANOVA) foi realizada com auxílio do programa computacional GENES (Cruz 2006), sendo utilizados todos os dados para análises das variáveis apenas em plantas autocompatíveis ou autoincompatíveis, e somente os valores de cada repetição (médias) para comparação entre os dois tipos de plantas.

Germinação in vitro - Os testes de germinação foram realizados conforme Ravindran (1977) - Teste 1, e conforme Bruckner et al. (2000) - Teste 2. Para o Teste 1 utilizou-se $150 \mathrm{~g} \mathrm{~L}^{-1} \mathrm{de}$ sacarose; $0,10 \mathrm{~g} \mathrm{~L}^{-1}$ de ácido bórico $\left(\mathrm{H}_{3} \mathrm{BO}_{4}\right)$; e $0,10 \mathrm{~g} \mathrm{~L}^{-1} \mathrm{de}$ nitrato de cálcio $\mathrm{Ca}\left(\mathrm{NO}_{3}\right)_{2}$. Para o Teste 2 utilizou-se $50 \mathrm{~g} \mathrm{~L}^{-1}$ de sacarose; $0,10 \mathrm{~g} \mathrm{~L}^{-1}$ de ácido bórico $\left(\mathrm{H}_{3} \mathrm{BO}_{4}\right) ; 0,30 \mathrm{~g} \mathrm{~L}^{-1}$ de nitrato de cálcio tetraidratado $\left(\mathrm{Ca}\left(\mathrm{NO}_{3}\right)_{2} .4 \mathrm{H}_{2} \mathrm{O}\right) ; 0,2 \mathrm{~g} \mathrm{~L}^{-1}$ de sulfato de magnésio heptaidratado $\left(\mathrm{MgSO}_{4} \cdot 7 \mathrm{H}_{2} \mathrm{O}\right)$; e $0,1 \mathrm{~g} \mathrm{~L}^{-1}$ de nitrato de potássio $\left(\mathrm{KNO}_{3}\right)$. Flores recém-abertas foram coletadas e os grãos de pólen (GP) foram liberados da antera delicadamente em lâmina com uma gota do meio de germinação, previamente autoclavado a $121^{\circ} \mathrm{C}$ por 15 minutos, e posteriormente cobertos com lamínula. $\mathrm{O}$ material foi mantido em estufa com diferentes temperaturas e tempos, de acordo com a recomendação para cada teste: Teste 1 temperatura de $35^{\circ} \mathrm{C}$ por até 5 horas de incubação; Teste 2 - temperatura de $28 \pm 1{ }^{\circ} \mathrm{C}$ por até 24 horas de incubação. Considerou-se como GP germinado aquele cujo tubo polínico apresentou comprimento mínimo duas vezes maior que o diâmetro médio do GP. Todos os GP contidos na lâmina foram contados.

Razão pólen-óvulo (P:O) - A razão $\mathrm{P}: \mathrm{O}$ foi utilizada como indicadora do modo de reprodução preferencial da planta.
Realizou-se a contagem do número total de grãos de pólen por antera e do número de óvulos por ovário. Botões florais ainda fechados foram coletados próximo ao momento da antese. Para a contagem dos grãos de pólen, estes foram liberados da antera, com auxílio de agulhas, em uma gota da solução de Alexander (Alexander 1969). Uma antera resultou em 2 a 3 lâminas, transferindo-se cada antera de uma lâmina à outra, para a retirada de todos os grãos de pólen e posterior contagem. As anteras foram observadas sob microscópio estereoscópico para confirmação da retirada de todos os GP. Para a contagem de óvulos foi utilizado o corante recomendado por Dafni (1992): 0,05 g de azul metileno $+20 \mathrm{~g}$ de fenol $+20 \mathrm{ml}$ de ácido lático $+40 \mathrm{ml}$ de glicerol $+20 \mathrm{ml}$ de água destilada. Os resultados médios foram utilizados para a classificação de Cruden (1977): cleistogamia $(<5,4)$; autogamia obrigatória (5,5-39); autogamia facultativa (39,1-396,9); alogamia facultativa (397-2.588); alogamia obrigatória $(>2.588)$.

\section{Resultados e discussão}

A performance do pólen diferiu em relação aos testes de germinação in vitro utilizados (tabela 1). O percentual de GP germinados in vitro foi, em média, maior nas plantas autoincompatíveis. O Teste 1, de Ravindran (1977), específico para o cacaueiro, resultou em maiores índices de germinação in vitro dos GP, acima de $70 \%$. Os resultados das análises de variância são apresentados nas tabelas 2 e 3 . Houve diferença significativa $(P<0,01)$ entre as repetições do clone autocompatível CCN51 para os dois testes utilizados. Entre as repetições do clone autoincompatível TSH1188, não houve diferença significativa para o Teste 1 , mas apenas para o Teste 2, principalmente em função de um dos genótipos ter apresentado $70 \%$ de germinação, enquanto os demais apresentaram entre $31,3 \%$ e $33,9 \%$. Houve diferença significativa para o Teste 1 quando comparados os clones CCN51 com TSH1188, o mesmo não ocorrendo para o Teste 2. De maneira geral, houve diferença significativa entre os clones autocompatíveis e autoincompatíveis, configurando variabilidade na performance polínica, de provável influência genotípica.

O número de grãos de pólen e de óvulos diferiu entre os genótipos analisados (tabela 1). Houve diferença significativa $(P<0,01)$ entre as plantas autocompatíveis e entre as autoincompatíveis para as características número de grãos de pólen, número de óvulos e razão P:O (tabela 2). Dias (2001) relata a existência de 14 mil grãos de pólen por flor de cacaueiro, mas em nossos estudos, o número de grãos de pólen observado nas plantas estudadas variou de 311 a 610 por antera, ou seja, no máximo 3.050 grãos de pólen por flor. Segundo Young 
Tabela 1. Dados médios de germinação in vitro de grãos de pólen (GP) utilizando-se dois testes, e da razão pólen-óvulo (P:O) em cacaueiros autocompatíveis e autoincompatíveis.

Table 1. Mean values of in vitro germination of pollen grain (GP) using two tests, and of pollen:ovule ratio (P:O) in selfcompatible and self-incompatible cacao trees.

\begin{tabular}{|c|c|c|c|c|c|c|c|c|}
\hline \multirow{3}{*}{\multicolumn{2}{|c|}{ Repetições* }} & \multicolumn{4}{|c|}{ Germinação in vitro } & \multicolumn{3}{|c|}{ Razão pólen-óvulo } \\
\hline & & \multicolumn{2}{|c|}{ Teste 1} & \multicolumn{2}{|c|}{ Teste 2} & \multirow{2}{*}{$\begin{array}{l}\text { № } \\
\text { GP }\end{array}$} & \multirow{2}{*}{$\begin{array}{l}\text { № de } \\
\text { óvulos }\end{array}$} & \multirow{2}{*}{$\begin{array}{c}\text { Razão } \\
\text { P:O }\end{array}$} \\
\hline & & GP contados & \% GP germinados & GP contados & $\%$ GP germinados & & & \\
\hline \multirow{6}{*}{ 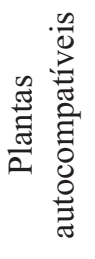 } & 1 & 528 & 81,1 & 178 & 31,5 & 513 & 61 & 8,4 \\
\hline & 2 & 367 & 78,5 & 444 & 45,5 & 537 & 70 & 7,6 \\
\hline & 3 & 445 & 70,1 & 371 & 28,8 & 311 & 68 & 4,5 \\
\hline & 4 & 629 & 75,6 & 727 & 46,8 & 367 & 59 & 6,2 \\
\hline & 5 & 458 & 81,1 & 561 & 39,2 & 560 & 60 & 9,3 \\
\hline & Médias & 485,4 & 77,3 & 456,2 & 38,4 & 457,6 & 63,6 & 7,2 \\
\hline \multirow{6}{*}{ 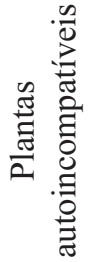 } & 1 & 359 & 88,1 & 300 & 70,0 & 597 & 64 & 9,3 \\
\hline & 2 & 334 & 91,5 & 160 & 31,3 & 478 & 59 & 8,1 \\
\hline & 3 & 297 & 89,7 & 200 & 32,0 & 610 & 68 & 8,9 \\
\hline & 4 & 288 & 90,0 & 301 & 33,9 & 399 & 61 & 6,5 \\
\hline & 5 & 303 & 88,2 & 331 & 32,6 & 340 & 69 & 4,9 \\
\hline & Médias & 316,2 & 89,50 & 258,4 & 40,0 & 484,8 & 58,2 & 7,5 \\
\hline
\end{tabular}

* Os valores de cada repetição correspondem à média de quatro flores analisadas. *The values of each repetition is the average of four flowers analyzed.

Tabela 2. Resumo da análise de variância dentro de plantas autocompatíveis (Ac) e dentro de plantas autoincompatíveis (Aic) de cacaueiros para o percentual de grãos de pólen germinados in vitro (G) utilizando o Teste 1 (T1) e o Teste 2 (T2), e para número de grãos de pólen (GP) e número de óvulos (NO). ( $\mathrm{GL}=$ Graus de liberdade; $\mathrm{CV}=$ Coeficiente de variação).

Table 2. ANOVA summary into self-compatible (AC) and into self-incompatible (Aic) in cacao trees in relation to in vitro germination percentage values of pollen grains (G) using test 1 (T1) and test 2 (T2), and in relation to number of pollen grains (GP) and ovules (NO). (GL = degrees of freedom; $\mathrm{CV}=$ coefficient of variation).

\begin{tabular}{lrrrrrrrrr}
\hline \multirow{2}{*}{$\begin{array}{l}\text { Fontes de } \\
\text { variação }\end{array}$} & \multirow{2}{*}{ GL } & \multicolumn{7}{c}{ Quadrados médios } \\
\cline { 2 - 9 } & & GAcT1 & GAcT2 & GAicT1 & GAicT2 & GPAc & GPAic & NOAc & NOAic \\
\hline Tratamentos & 4 & $412,645^{* *}$ & $1306,86^{* *}$ & $40,014^{\text {NS }}$ & $5658,26^{* *}$ & $61949,0^{* *}$ & $70798,5^{* *}$ & $126,5^{* *}$ & $93,5^{* *}$ \\
Erro & 20 & 230,032 & 405,68 & 139,112 & 76,28 & 729,0 & 427,0 & 8,50 & 7,0 \\
CV (\%) & & 4,390 & 11,74 & 2,94 & 4,88 & 5,90 & 4,26 & 4,58 & 4,12 \\
\hline
\end{tabular}

${ }^{* *}$ Significativo em nível de $1 \%(P<0,01)$ de probabilidade pelo teste F; NS Não significativo. Significant at $1 \%$ level $(\mathrm{P}<0,01)$ at $\mathrm{F}$ test; ${ }^{\mathrm{NS}}=$ not significant.

et al. (1987), são necessários apenas de 30 a 60 grãos de pólen para que a fertilização seja bem sucedida.

Não houve diferença significativa para as características número de grãos de pólen, número de óvulos e razão P:O quando comparados os clones CCN51 e TSH1188 (tabela 3). Segundo Cruden (1977), os resultados indicam que ambas as plantas foram classificadas como autógamas obrigatórias. Tendo em vista a autoincompatibilidade observada em TSH1188, concluímos que houve um desvio do padrão sugerido por Cruden, conforme já relatado por outros autores para diferentes espécies (Dafni 1992). 
Tabela 3. Resumo da análise de variância entre plantas autocompatíveis e autoincompatíveis de cacaueiros para o percentual de grãos de pólen germinados in vitro utilizando o Teste 1 (T1) e o Teste 2 (T2), para número de grãos de pólen (NGP), número de óvulos (NO) e para razão pólen-óvulo (RPO). (GL = Graus de liberdade; $\mathrm{CV}=$ Coeficiente de variação)

Table 3. ANOVA summary among self-compatible and self-incompatible plants of cacao trees in relation to in vitro germination percentage values of pollen grains using test 1 (T1) and test 2 (T2), number of pollen grains (NGP) and ovules (NO), and pollen-ovule ratio (RPO). (GL = degrees of freedom; $\mathrm{CV}=$ coefficient of variation).

\begin{tabular}{lcccccc}
\hline \multirow{2}{*}{ Fontes de variação } & \multirow{2}{*}{ GL } & T1 & T2 & NGP & NO & RPO \\
\cline { 3 - 7 } & 1 & $373,321^{* *}$ & $6,400^{\text {NS }}$ & $1849,6^{\text {NS }}$ & $0,9^{\text {NS }}$ & $0,289^{\text {NS }}$ \\
Tratamentos & 8 & 92,98 & 1393,02 & 13274,75 & 22,00 & 3,45 \\
Erro & 4,08 & 33,69 & 24,45 & 7,34 & 25,20 \\
CV $(\%)$ & & & &
\end{tabular}

${ }^{* *}$ Significativo em nível de $1 \%(P<0,01)$ de probabilidade pelo teste F; ${ }^{\text {NS }}$ Não significativo. Significant at $1 \%$ level $(\mathrm{P}<0,01)$ at $\mathrm{F}$ test; ${ }^{\mathrm{NS}}=$ not significant.

Agradecimentos - A pesquisa é parte integrante da Iniciação Científica Júnior da primeira autora. À Fapesb pelo financiamento à pesquisa e pela bolsa de IC Jr. concedida à primeira autora, e à Ceplac $(\mathrm{BA})$, pela permissão para a utilização dos clones mantidos em seu Banco de Germoplasma de Cacaueiros.

\section{Referências bibliográficas}

ALEXANDER, M.P. 1969. Differential staining of aborted and non-aborted pollen. Stain Technology 44:117-122.

BRUCKNER, C.H., SILVA, M.M., FALLEIRO, T.M., ANDRADE, B.B. \& MOREIRA, A.E. 2000. Viabilidade do pólen de maracujazeiro sob diferentes condições de armazenamento. Revista Ceres 47:523-531.

CARLETTO, G.A. \& SORIA, J. 1973. Testes de graus de incompatibilidade em vários cacaueiros (Theobroma cacao L.). Revista Theobroma 3:26-35.

CASTRO, G.C.T. \& BARTLEY, B.G.D. 1983. Caracterização dos recursos genéticos do cacaueiro. 1. Folha, fruto e semente de seleções da Bahia das séries SIC e SIAL. Revista Theobroma 13:263-273.

CRUDEN, R.W. 1977. Pollen-ovule ratios: a conservative indicator of breeding systems in flowering plants. Evolution 31:32-46.

CRUZ, C.D. 2006. Programa Genes - estatística experimental e matrizes. Editora UFV, Viçosa.

DAFNI, A. 1992. Pollination ecology, a practical approach. Oxford University Press, New York.
DIAS, L.A.S. 2001. Melhoramento genético do cacaueiro. Funape/UFG, Viçosa.

ENRIQUEZ, G.A. 1985. Curso sobre el cultivo del cacao. Centro Agronómico Tropical de Investigación y Enseñanza, Turrialba, Costa Rica.

MÜLLER, M.W. \& VALLE, R.R. 2007. Ecofisiologia do cultivo do cacaueiro. In Ciência, tecnologia e manejo do cacaueiro (R.R. Valle, ed.). Gráfica e Editora Vital Ltda., Itabuna, p.17-41.

NETTANCOURT, D. 1977. Incompatibility in angiosperms. Springer, Berlin.

PINTO, L.R.M., YAMADA, M.M. \& AHNERT, D. 1998. Recomendações para determinação da incompatibilidade sexual no cacaueiro. Ceplac/Ministério da Agricultura, Ilhéus.

RAVINDRAN, P.N. 1977. In vitro germination and growth of cacao pollen. Journal of Plantation Crops 5:109-111.

SOUZA, M.M., PEREIRA, T.N.S. \& MARTINS, E.M. 2002. Microsporogênese e Microgametogênese associadas ao tamanho do botão floral e da antera e viabilidade polínica em maracujazeiro-amarelo. Ciência e Agrotecnologia 26:1209-1217.

YOUNG, A.M. 1982. Effects of shade cover and availability of midge breeding sites on pollinating midge populations and fruit set in two cocoa farms. The Journal of Applied Ecology. 19:47-63.

YOUNG, A.M., ERICKSON, E.H., STRAND, M.A. \& ERICKSON, B.J. 1987. Pollination biology of Theobroma and Herrania (Sterculiaceae) - I. Floral biology. Insect Science and Application 8:151-164. 